\title{
Evolution strategies based coefficient of TSK fuzzy forecasting engine
}

\author{
Nadia Roosmalita Sari ${ }^{a, 1}$, Wayan Firdaus Mahmud ${ }^{b, 2}$, Aji Prasetya Wibawa ${ }^{c, 3, *}$ \\ ${ }^{a}$ Faculty of Islamic's Economic and Business, Institut Agama Islam Negeri Tulungagung, Jl.Mayor Sujadi 46, Tulungagung 66221, Indonesia \\ ${ }^{b}$ Faculty of Computer Science, Universitas Brawijaya, J. Veteran Malang, Malang 65145, Indonesia \\ ' Department of Electrical Engineering, Universitas Negeri Malang, Jl. Semarang 5, Malang 65145, Indonesia \\ ${ }^{1}$ nadiaroosmalitasari@gmail.com; ${ }^{2}$ wayanfm@ub.ac.id; ${ }^{3}$ aji.prasetya.ft@um.ac.id \\ * corresponding author
}

\section{ARTICLE INFO}

\section{Article history}

Received August 29, 2019

Revised July 23, 2020

Accepted March 26, 2021

Available online March 31, 2021

\section{Keywords}

Evolution Strategies

TSK fuzzy logic

Inflation rate

Forecasting

Mean Square Error

\section{ABSTRACT}

Forecasting is a method of predicting past and current data, most often by pattern analysis. A Fuzzy Takagi Sugeno Kang (TSK) study can predict Indonesia's inflation rate, yet with too high error. This study proposes an accuracy improvement based on Evolution Strategies (ES), a specific evolutionary algorithm with good performance optimization problems. ES algorithm used to determine the best coefficient values on consequent fuzzy rules. This research uses Bank Indonesia time-series data as in the previous study. ES algorithm uses the popSize test to define the number of initial chromosomes for the best optimal solution production. The increase of popSize creates better fitness value due to the ES's broader search area. The RMSE of ES-TSK is 0.637 , which outperforms the baseline approach. This research generally shows that ES may reduce repetitive experiment events due to Fuzzy coefficients' manual setting. The algorithm complexity may cost to the computing time, yet with higher performance.

This is an open access article under the CC-BY-SA license.

\section{Introduction}

Evolution Strategies (ES) is a specialization of the evolutionary algorithm. ES works very well with optimization problems [1]. in various areas from 2000 to the present [2]. ES is a population-based algorithm suitable for complex mathematical model-based issues [3]. This method is similar to GA, has a high success rate in resolving the optimization problems [4]. ES performs well in generating the ruleset of Intrusion Detection Systems (IDS) [5] and effective for large-scale vehicle routing problems with time windows [6]. ES algorithm is explicitly designed for high-dimensional searching space [7]. The result showed that ES could provide the best solution to $86 \%$ of all test instances within reasonable computing times.

Evolution Strategies is suitable for nonlinear problems, such as forecasting. Forecasting estimates future occasions or values based on past and current facts [8]. It uses an irregular and inconsistent pattern of historical data as a base of time-series analysis [9]. The techniques are various, including Fuzzy Inference System (FIS) Takagi Sugeno Kang (TSK) method with time-series analysis [10], which is effective for time-series such as inflation rate.

Inflation is a decline in the buying power of capital. The indicator is a rise in the prices of goods and services throughout an economy [11]. Internal or external factors may cause inflation. Inflation in the country occurs due to unpredictable circumstances because of society's behavior and the government. Inflation may pressure domestic prices through imported goods. If the currency decreases, it may lead 
to the country's cheaper values while imports from other countries become more expensive. In general, the impact of rising inflation affects the sale value of goods in the market. The high-priced daily necessities may disrupt society. Therefore, forecasting the inflation rate is considered necessary for the government to anticipate rising inflation.

TSK Fuzzy is one of the popular forecasting approaches. The TSK fuzzy logic has the advantage of explaining things well [12]. The TSK fuzzy logic very popular in some research on time-series data [10], control [13] [14], modeling [15] [16], classification [17]. This model is also widely used for issues related to forecasting, as in the researches that were conducted by Gharlegi et al. [15], Sarip et al. [18], Du et al. [19], Pattanayak et al. [20], and Chang et al. [21]. Sarip et al. [18] used the fuzzy model for real estate price prediction. However, these studies manually determined the coefficient on fuzzy rules, resulting in insufficient accuracy. To find the appropriate coefficient need many experiments, which takes much time.

This study proposes an evolution strategies (ES) coefficient of TSK fuzzy logic to predict the future inflation rate. ES was selected since this algorithm has a self-adaptation mechanism to control the value of the searching coefficient [22]. This algorithm imitates the genetic processes in living organisms, which is natural generation development, which gradually follows the natural selection process [4]. By mimicking this evolution theory, the correct coefficient values based on rules can create optimal system performance. It is essential to determine the coefficient values correctly based on rules used in the defuzzification phase so that the forecasting result closer to the actual data.

\section{Method}

\subsection{Consideration on Modeling of Generating Coefficient Value in Fuzzy Rules}

The initial step made a mathematical model that addresses the fuzzy rules. The model represents the consequent in every TSK fuzzy rule. For better accuracy, the heuristic method determines the correct coefficient values [23]. This study determines the initial coefficient using time-series analysis. Furthermore, that coefficient was used as an initial chromosome.

A real-code ES chromosome is designed to obtain the appropriate coefficient value on fuzzy rules to produce the optimal solution with minimal computation time. Fig. 1 shows the coefficient optimization process on TSK fuzzy rules using ES. Time-series analysis for inflation rate forecasting is used as a baseline to justify the ES performance.

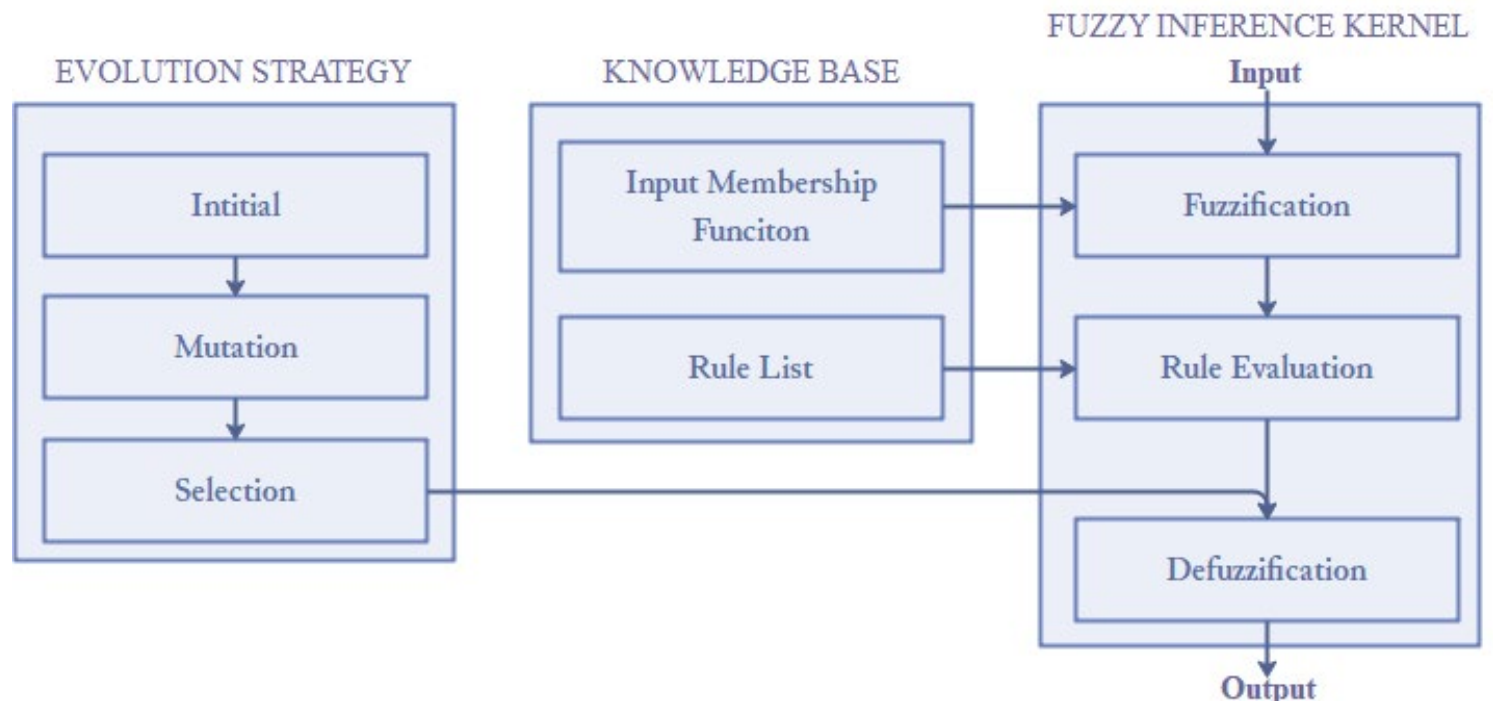

Fig. 1. Block diagram of the coefficient optimization process on fuzzy rules using Evolution Strategies 
The data used to obtained forecasting is statistical data from Bank Indonesia (151 time-series data record) [24]. Table 1 shows the coefficient value that used in time-series analysis. The existing timeseries data was then formed into a cycle. The cycle creation was based on the parameters used. These parameters are from one month prior, two months prior, and three months prior. Table 2 shows the parameters used in the time-series analysis technique.

Table 1. The coefficient of time-series analysis

\begin{tabular}{cc}
\hline Variables & Coefficient Value \\
\hline Intercept $(\mathrm{a})$ & 0.550213714 \\
X Variable $1\left(\mathrm{~b}_{1}\right)$ & 1.158290955 \\
X Variable 2 $\left(\mathrm{b}_{2}\right)$ & -0.280088718 \\
X Variable 3 $\left(\mathrm{b}_{3}\right)$ & 0.044275969 \\
\hline
\end{tabular}

Table 2. Parameters properties

\begin{tabular}{cc}
\hline Parameters & Description \\
\hline $\mathrm{Y}(\mathrm{b}-1)$ & One month prior \\
$\mathrm{Y}(\mathrm{b}-2)$ & Two months prior \\
$\mathrm{Y}(\mathrm{b}-3)$ & Three months prior \\
\hline
\end{tabular}

By using time-series analysis, the RMSE (Root Mean Square Error) is 1.150004833. Fig. 2 shows quite a good movement where the time-series analysis technique almost approaches the actual data curve.

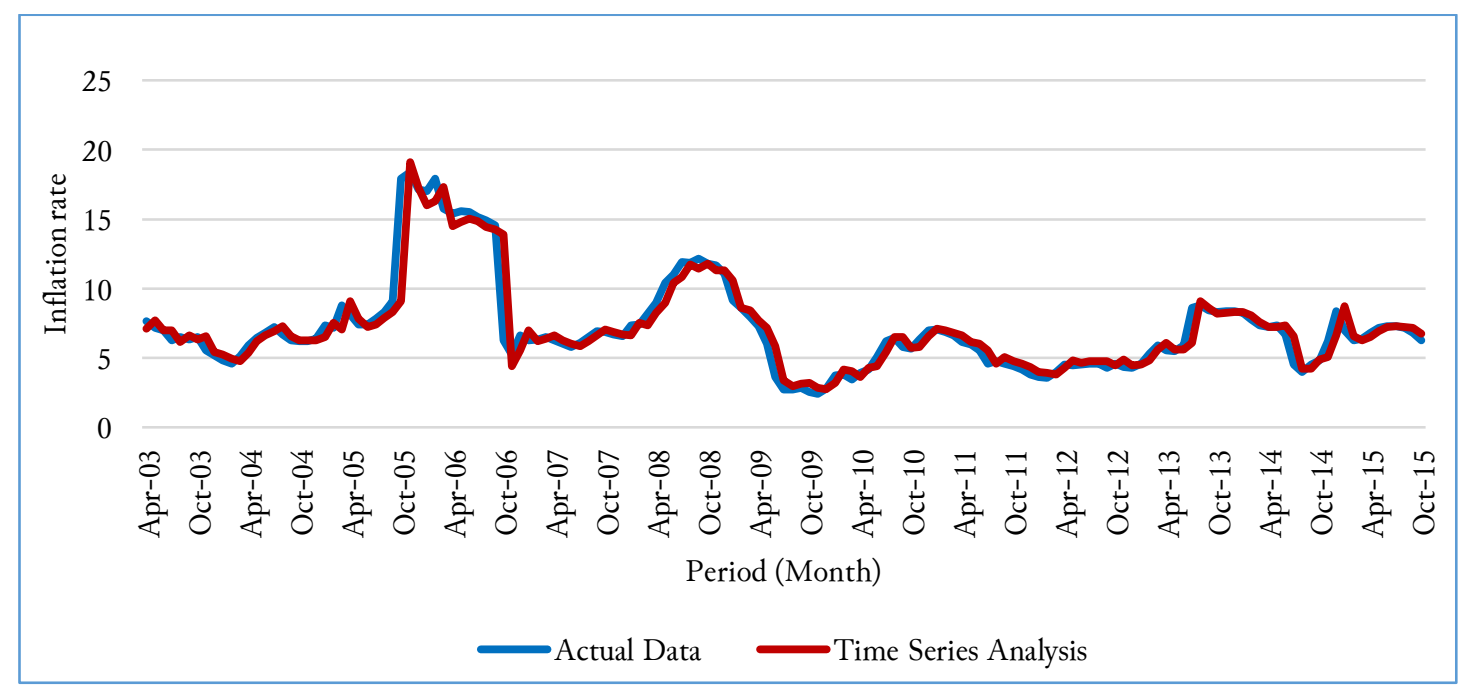

Fig. 2. Testing result using time-series analysis for inflation rate forecasting

\subsection{Implementation of TSK Fuzzy Logic}

Zadeh introduces fuzzy logic in 1975 [4]. This research used TSK fuzzy logic to overcome several other studies' weaknesses for forecasting problems. Many authors are interested in the TSK fuzzy logic model for its simple and reasonably practical computation. The implementation of TSK fuzzy logic is effective in various areas such as modeling and control, classification, forecasting, and others [4]. ES may optimize the accuracy of such systems.

\subsubsection{Fuzzification}

In fuzzy logic, not all decisions are resolved by 0 or 1 ; some conditions fall between both, namely "fuzzy" or disguised. Fuzzification is the chaining process of the crisp values into the membership function. The fuzzy membership function represents the input data into the membership value with a range between 0 to 1 [23]. In the fuzzification process, the parameters are defined as input variables (Table 2). The output variables in this study are the forecasting results. 
A fuzzy set is a union that represents a specific condition in the variable [25]. The fuzzy logic variable has a set of values characterized by the linguistic expression [26]. This study divide input variable (Table 2) into three fuzzy sets, namely DESCENDING, CONSTANT, and ASCENDING [23][27]. Expert opinions have adjusted the determination of fuzzy sets. Fuzzy membership limitations on the input variables are in real numbers. The DESCENDING fuzzy set has a domain [(-10)-0], ASCENDING with domain $[0-10]$, and CONSTANT [(-2) - 2], as shown in Fig. 3.

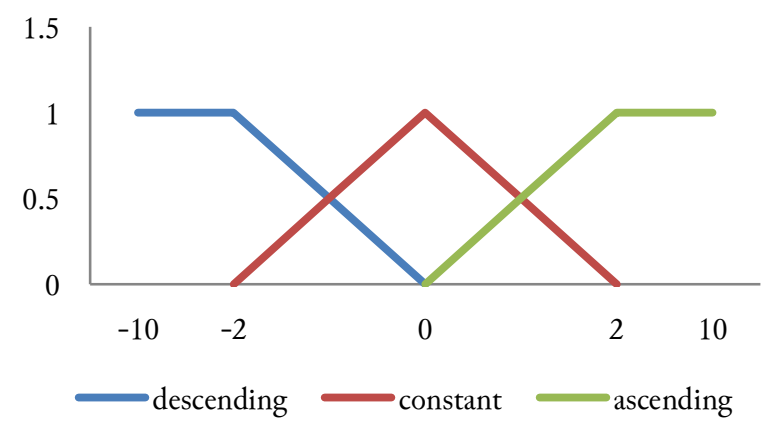

Fig. 3. Membership function of input variables

The fuzzy sets domains were selected based on the deviation calculation between the forecasting results using time-series analysis and actual data shown in Fig. 4.

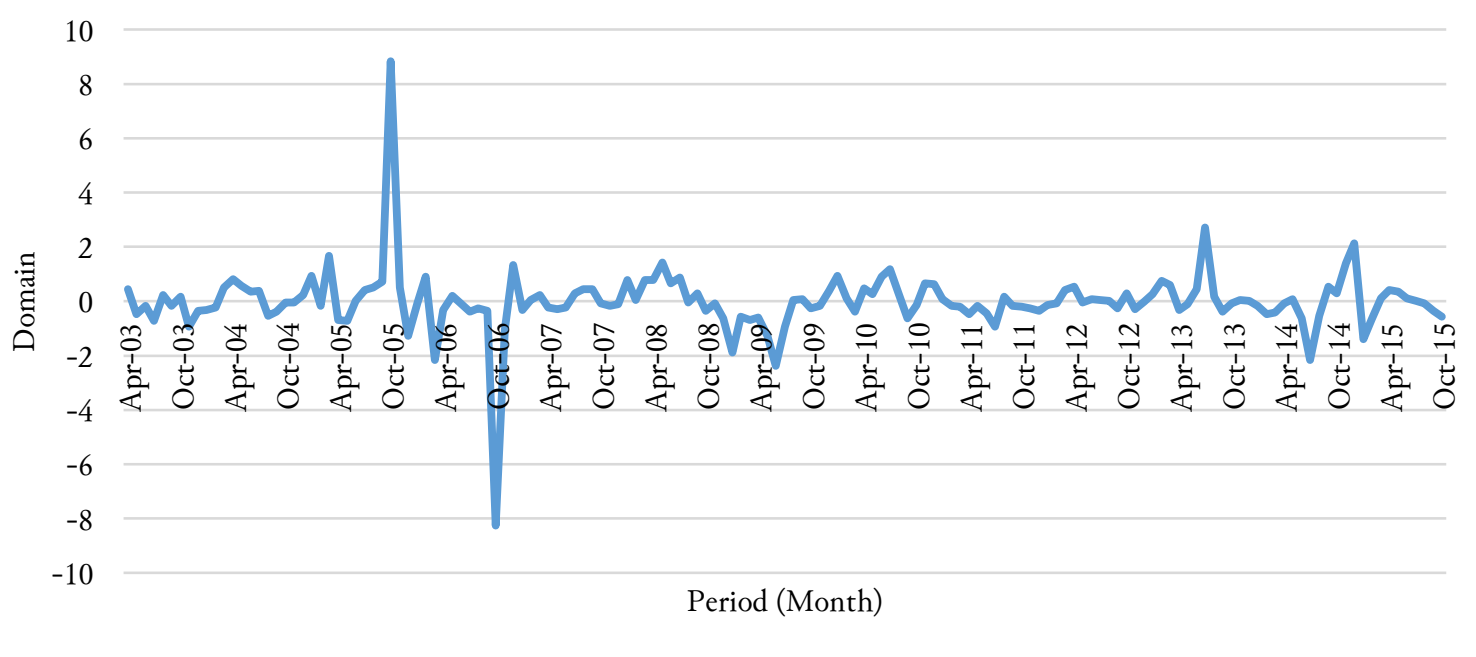

Fig. 4. Determining fuzzy set domain using time-series analysis

The membership function in every set is formulated in Eq. (1), (2), and (3), where $\mu$ is the degree of membership and $x$ is the subject set.

$$
\begin{aligned}
& \mu \text { Descending }(x)=\left\{\begin{array}{cl}
\frac{1}{0-x} & x \leq(-2) \\
0 & (-2<x<2)
\end{array}\right. \\
& \mu \text { Constant }(x)=\left\{\begin{array}{cl}
\frac{x-(-2)}{0-(-2)} & (-2 \leq x \leq 0) \\
\frac{1}{2-x} & x \leq x \leq 2
\end{array}\right. \\
& \mu \text { Ascending }(x)=\left\{\begin{array}{cl}
0 & x \leq-2) \text { or } x \geq 2 \\
\frac{x-0}{2} & x \leq 0 \\
1 & x \geq 2
\end{array}\right.
\end{aligned}
$$




\subsubsection{Fuzzy Inference Rules}

In this process, the result of fuzzy membership value calculation is inferred to the fuzzy rules. The fuzzy logic control's basic rules are in the form "IF -THEN" of the first order, wherein after IF is a fuzzy set as antecedent and after THEN is the linear equation as a consequent.

Three input variables need to be implemented to the fuzzy rules [28]. The number of rules was determined by squaring the fuzzy set with input variables. In this case, the number of rules of 3 raised to the power of 3 is equal to 27 rules that are obtained from all combinations of inputs that are described in Eq. (4) [21].

$$
\left[R_{i}\right] \operatorname{IF}\left(x_{1} \text { is } A_{1}\right)^{\circ}\left(x_{2} \text { is } A_{2}\right)^{\circ} \text {. }^{\circ} x_{n} \text { is } A_{n} \text { THEN } z_{n}=q+p_{1} * x_{1}+\cdots+p_{n} * x_{n}
$$

Where $R i$ is $i^{\text {th }}$ fuzzy rule ( $\left.\mathrm{i}=1 \ldots \mathrm{n}\right), X_{n}$ for $n^{\text {th }}$ parameter, $A_{n}$ is fuzzy set in the $n^{\text {th }}$ parameter that relevant to the $n^{\text {th }}$ rule, $Z_{n}$ is $n^{\text {th }}$ linear equation, $q$ is coefficient inconsequent, $p_{n}$ for $n^{\text {th }}$ constant, and o represents an operator AND. Membership functions used in the fuzzification process are with values of each input variables $\mathrm{Y}(\mathrm{b}-1), \mathrm{Y}(\mathrm{b}-2)$, and $\mathrm{Y}(\mathrm{b}-3)$ to the existing fuzzy sets. Some of the rules used in this study are described in Table 3.

Table 3. The establishment of the rules

\begin{tabular}{cl}
\hline $\mathrm{Rn}$ & \multicolumn{1}{c}{ Fuzzy Rules } \\
\hline $\mathrm{R}_{1}$ & IF $\mathrm{Y}(\mathrm{b}-1)$ is descending AND $\mathrm{Y}(\mathrm{b}-2)$ is descending AND $\mathrm{Y}(\mathrm{b}-3)$ is descending \\
& THEN $Z n=\mathrm{a}+\mathrm{b}_{1} \mathrm{Y}(\mathrm{b}-1)+\mathrm{b}_{2} \mathrm{Y}(\mathrm{b}-2)+\mathrm{b}_{3} \mathrm{Y}(\mathrm{b}-3)$ \\
$\mathrm{R}_{2}$ & IF $\mathrm{Y}(\mathrm{b}-1)$ is descending AND $\mathrm{Y}(\mathrm{b}-2)$ is ascending AND $\mathrm{Y}(\mathrm{b}-3)$ is constant \\
& THEN $Z n=\mathrm{a}+\mathrm{b}_{1} \mathrm{Y}(\mathrm{b}-1)+\mathrm{b}_{2} \mathrm{Y}(\mathrm{b}-2)+\mathrm{b}_{3} \mathrm{Y}(\mathrm{b}-3)$ \\
$\mathrm{R}_{3}$ & IF $\mathrm{Y}(\mathrm{b}-1)$ is ascending AND $\mathrm{Y}(\mathrm{b}-2)$ is constant AND $\mathrm{Y}(\mathrm{b}-3)$ is descending \\
& THEN $Z n=\mathrm{a}+\mathrm{b}_{1} \mathrm{Y}(\mathrm{b}-1)+\mathrm{b}_{2} \mathrm{Y}(\mathrm{b}-2)+\mathrm{b}_{3} \mathrm{Y}(\mathrm{b}-3)$
\end{tabular}

\subsubsection{Defuzzification}

Defuzzification remaps the fuzzy values into the clear solution values. The output is a numerical member of the fuzzy set domain. The rule base's establishment find the value of $\alpha$-predicate to each rule $\left(\alpha_{i}\right)$. The $\alpha$-predicate value depends on the operator and the implication of used functions. The AND operator with the MIN implications function is used to find a minimum value on each rule and to obtain the value of $\alpha$-predicate. The acquisition value of $\alpha$-predicate described in (5) [29], which $\alpha_{n}$ is $\alpha$-predicate value on the $n^{\text {th }}$ rule, $\mu_{n}$ is the degree of membership on the $n^{\text {th }}$ rule, and $x_{n}$ is the $n^{t h}$ parameter.

$$
\alpha_{n}=\mu_{A_{1} \cap A_{2} \cap \ldots \cap A_{n}}=\min \left(\mu_{A_{1}}\left(x_{1}\right), \mu_{A_{2}}\left(x_{2}\right), \ldots, \mu_{A_{n}}\left(x_{n}\right)\right.
$$

The calculation of each consequent's value was done appropriately to the membership function used after obtaining the $\alpha$-predicate. In the defuzzification process, the Center Average Defuzzifier method is used as in (6) [30] [31].

$$
Z=\sum_{i}^{n} \alpha_{i} z_{i} \frac{\sum_{i=1}^{n} \alpha_{i} z_{i}}{\sum_{i=1}^{n} \alpha_{i}}
$$

$Z$ is the result of defuzzification, while $\alpha_{i}$ is the antecedent membership value, and $z_{i}$ is the inference result of each rule.

\subsection{Numerical Example}

The correct parameters have to be determined correctly. It may produce the optimal system performance. In doing so, the forecasting results can be more accurate. For that, an experiment is needed to find the proper parameters. This study uses 50 data records for testing the small-scale data. The data were taken from the inflation rate data in October 2011 - October 2015 [24]. Fuzzy rules are used to 
obtain the coefficient values used to represent chromosomes in testing using ES. The rules that were formed are the 27 rules shown in Table 3. TSK fuzzy output is a regression equation with the same coefficient in every rule. That coefficient used is the initial chromosome representation. Table 4 shows the coefficient value of the regression equation with 50 data records.

Table 4. The value of regression coefficient using 50 data records and 3 parameters

\begin{tabular}{cc}
\hline Variables & Coefficient Value \\
\hline Intercept (a) & 0.702713938 \\
x variable 1 (b1) & 1.253927166 \\
x variable 1 (b1) & -0.570497404 \\
x variable 1 (b1) & 0.203109555 \\
\hline
\end{tabular}

Some notations are used in the testing process using ES. $\mu$ (miu) states the size of the population (PopSize), while $\chi$ (lambda) stands for the number of produced offspring in the reproductive process. ES $(\mu+\chi)$ is ES without recombination and selection process that involves individual offspring and parents. Some studies suggest the value of $\chi$ as $7 \mu$ [7]. This study did the initial testing by using the multiplier 7 to determine the correct amount of PopSize. Some amounts of PopSize that are different have been tested by the multiplier 7 and produce the separate offspring that are shown in Table 5. This test was done 10 times to find out the right PopSize.

Table 5. Determining of appropriate PopSize

\begin{tabular}{|c|c|c|c|c|c|c|c|}
\hline \multirow{2}{*}{ Multiplier } & \multirow{2}{*}{$\begin{array}{c}\text { Miu } \\
(\mu)\end{array}$} & \multirow{2}{*}{$\begin{array}{l}\text { Lambda } \\
(\Lambda)\end{array}$} & \multicolumn{3}{|c|}{ Fitness Testing } & \multirow{2}{*}{$\begin{array}{l}\text { Fitness } \\
\text { Average }\end{array}$} & \multirow{2}{*}{$\begin{array}{l}\text { Running Time } \\
\text { (Minute) }\end{array}$} \\
\hline & & & 1 & $\ldots$ & 10 & & \\
\hline 7 & 10 & 70 & 0.8538851 & $\ldots$ & 0.8423915 & 0.8474712 & 6 \\
\hline 7 & 15 & 105 & 0.8550591 & $\ldots$ & 0.8534622 & 0.8554894 & 6 \\
\hline 7 & 20 & 140 & 0.8566549 & $\ldots$ & 0.857978 & 0.8553069 & 8 \\
\hline 7 & 25 & 175 & 0.8649389 & $\ldots$ & 0.8632854 & 0.8613305 & 10 \\
\hline 7 & 30 & 210 & 0.869523 & $\ldots$ & 0.8665028 & 0.8679571 & 12 \\
\hline 7 & 35 & 245 & 0.8646665 & $\ldots$ & 0.8701335 & 0.8687701 & 13 \\
\hline 7 & 40 & 280 & 0.8691789 & $\ldots$ & 0.8674864 & 0.8666617 & 15 \\
\hline 7 & 45 & 315 & 0.8769686 & $\ldots$ & 0.8746194 & 0.8729461 & 17 \\
\hline 7 & 50 & 350 & 0.878492 & $\ldots$ & 0.8781025 & 0.8766926 & 19 \\
\hline 7 & 100 & 700 & 0.8802493 & $\ldots$ & 0.8829275 & 0.8827496 & 38 \\
\hline 7 & 150 & 1050 & 0.8918057 & $\ldots$ & 0.8883632 & 0.8878138 & 57 \\
\hline 7 & 200 & 1400 & 0.895102 & $\ldots$ & 0.8902145 & 0.8910451 & 74 \\
\hline 7 & 250 & 1750 & 0.8943427 & $\ldots$ & 0.8906058 & 0.890965 & 93 \\
\hline 7 & 300 & 2100 & 0.8905459 & $\ldots$ & 0.8936155 & 0.8922971 & 115 \\
\hline 7 & 500 & 3500 & 0.8924948 & $\ldots$ & 0.8909901 & 0.8936513 & 189 \\
\hline 7 & 800 & 5600 & 0.8950157 & $\ldots$ & 0.8984894 & 0.8977727 & 300 \\
\hline 7 & 1300 & 9100 & 0.898636 & $\ldots$ & 0.8973846 & 0.8996141 & 490 \\
\hline 7 & 2000 & 14000 & 0.9035377 & $\ldots$ & 0.8999164 & 0.900355 & 759 \\
\hline 7 & 5000 & 35000 & 0.9036517 & $\ldots$ & 0.9026019 & 0.9031863 & 1892 \\
\hline 7 & 7000 & 49000 & 0.9052033 & $\ldots$ & 0.9043052 & 0.9047805 & 2649 \\
\hline
\end{tabular}

In those tests the appropriate PopSize was obtained based on the highest average of the fitness. Fig. 5 shows that the highest average of the fitness is on the PopSize of 7000. However, on the PopSize of 1300, the average of fitness began to show quite a significant movement even though the value was not the best 
fitness. PopSize of 1300 was selected as its fitness average has the best approach with the faster computation time. On the other hand, PopSize was selected because the fitness value is steady at a certain point. The average fitness value of PopSize 10 to 1300 is increasing and tends to be stable after 1300. PopSize of 1300 with a multiplier of 7 could be used as a reference for large-scale data testing. The data used 151 data records of time-series inflation rate data [24].

\subsection{Optimization Coefficient on Fuzzy Rules Using ES}

The rule base coefficient value must be determined correctly to obtain the optimum system performance by numerous testing. Therefore, the ES algorithm may appropriately use to find the correct coefficient value to get the optimal or nearly optimal problem's solution. The main problem in the optimization technique using ES is in designing the chromosome. Chromosome representation is intended to produce the best solutions and minimize computation time [32]. In this case, a real coded model of a chromosome is proposed. In this study, the initial chromosome used the coefficients obtained from regression analysis shown in Table 1. Evolution Strategies has three major operators, which are recombination, mutation, and Selection [7].

\subsubsection{Mutation Process}

Every generation produces a new chromosome (offspring) by using genetic operators [33], recombination and mutation. The homogenous population may drop the effectiveness of recombination into its minimal [7]. As a result, mutation becomes the best way produce new offspring [34]. The mutation rate parameter or the probability mutation $(\mathrm{pm})$ defines the number of mutated chromosomes in a population. The mutation process was conducted by the random generation method.

For the example, there are two individuals selected, denoted by $P=\left(g_{1}, g_{2}, \sigma_{1}, \sigma_{2}\right)$. After the process of mutation, the resulting offspring is $P^{\prime}=\left(g^{\prime}{ }_{1}, g^{\prime}{ }_{2}, \sigma_{1}^{\prime}, \sigma_{2}^{\prime}\right)$. The resulting new chromosome described in (7) [22].

$$
g_{1}^{\prime}=g_{1}+\sigma_{1} N(0.1)
$$

where $N(0.1)$ is a random number, formed by two random numbers denoted by $x_{1}$ and $x_{2}$ in the intervals 0 and 1. Eq. (8) describes the formula of $N(0.1)$.

$$
N(0.1)=\sqrt{-2 \cdot \ln r_{1}} \sin 2 \pi r_{2}
$$

Self-adaptation is formed of calculation steps $\sigma$ in chromosomes, accomplished changing variations, and Selection. This mutation replaces the parents with offspring [22].

\subsubsection{Selection}

During the reproductive stage, all of the offspring produced by the mutation process are stored in the offspring pool. The selection method is used to determine the selected individuals from the population, and the offspring will proceed to the next generation. The Selection that is proposed is elitism selection. This method involves the individual in offspring and also parents. Offspring or parents in the population will be selected if they have the best fitness value [33].

\subsection{Dataset}

This research applies time-series monthly data of Indonesian inflation, obtained from Bank Indonesia between December 2002-October 2015 [24]. Table 6 shows the example of total 151 data records. The data was used as input to forecast the future inflation rate based on the time-series data.

The inflation rate has a well-ordered pattern. The pattern is created from the inflation rate cycle on the time-series data shown in Table 8. The cycle was formed based on the data of one month prior $Y(b-$ 1), two months prior $Y(b-2)$, and the three months prior $Y(b-3)$. Table 7 shows the cycle used for forecasting the inflation rate by using the time-series analysis approach and TSK fuzzy that is optimized using evolution strategy. 
Table 6. Example of inflation rate data

\begin{tabular}{cc}
\hline Months & Actual \\
\hline 3-Apr & 7.62 \\
3-May & 7.15 \\
3-Jun & 6.98 \\
3-Jul & 6.27 \\
3-Aug & 6.51 \\
15-Sep & $\ldots$ \\
15-Oct & 6.83 \\
\hline
\end{tabular}

Table 7. The cycle of time-series data for inflation rate forecasting

\begin{tabular}{ccccc}
\hline Months & Actual Data & $\boldsymbol{Y}(\boldsymbol{b}-\mathbf{1})$ & $\boldsymbol{Y}(\boldsymbol{b}-\mathbf{2})$ & $\boldsymbol{Y}(\boldsymbol{b}-\mathbf{3})$ \\
\hline 3-Apr & 7.62 & 7.17 & 7.6 & 8.68 \\
3-May & 7.15 & 7.62 & 7.17 & 7.6 \\
3-Jun & 6.98 & 7.15 & 7.62 & 7.17 \\
3-Jul & 6.27 & 6.98 & 7.15 & 7.62 \\
3-Aug & 6.51 & 6.27 & 6.98 & 7.15 \\
$\ldots$ & $\ldots$ & $\ldots$ & $\ldots$ & $\ldots$ \\
15-Sep & 6.83 & 7.18 & 7.26 & 7.26 \\
15-Oct & 6.25 & 6.83 & 7.18 & 7.26 \\
\hline
\end{tabular}

\section{Results and Discussion}

This study used the analysis parameters in the optimization process. The PopSize was 1300 with 7 as the multiplier. This parameter was used to produce the best fitness value with the large-scale data. As described in Section 2.3, the regression equation lies in the consequent fuzzy rules. This test used 1000 iterations to obtain the best fitness.

The best fitness value with 1000 iterations on the ES process has been obtained. The fitness value is selected through the various regeneration processes. The selected individuals were used to calculate defuzzification on TSK fuzzy; thus, crisp numbers were obtained as the output forecasting.

Table 8 shows the forecasting comparison between time-series analysis and the TSK fuzzy logic with Evolution Strategy (ES-TSK). The difference between the actual data and the forecasting results (error) are then squared to get the RMSE.

Table 8. Error comparison between ES-TSK algorithm and time-series analysis

\begin{tabular}{cccccc}
\hline Month & Actual & $\begin{array}{c}\text { Time-Series } \\
\text { Analysis }\end{array}$ & Error & ES-TSK & Error \\
\hline 3-Apr & 7.62 & 7.110801 & 0.2592836 & 7.8991695 & 0.0779356 \\
3-May & 7.15 & 7.704652 & 0.3076389 & 6.9810952 & 0.0285288 \\
3-Jun & 6.98 & 7.0151767 & 0.0012374 & 6.6235663 & 0.1270449 \\
3-Jul & 6.27 & 6.9698331 & 0.4897664 & 6.1592311 & 0.0122697 \\
3-Aug & 6.51 & 6.1742519 & 0.1127268 & 6.5962481 & 0.0074387 \\
3-Sep & 6.33 & 6.6435778 & 0.0983311 & 5.9608067 & 0.1363037 \\
$\ldots$ & $\ldots$ & $\ldots$ & $\ldots$ & $\ldots$ & $\ldots$ \\
15-Oct & 6.25 & 6.7717475 & 0.2722204 & 6.3081746 & 0.0033843 \\
RMSE & 1.1500048 & - & 0.6201362 & - & 1.1500048 \\
\hline
\end{tabular}


The RMSE of testing the ES-TSK algorithm is 0.6201. While in the comparison method that is time-series analysis, RMSE was 1.1500. The smaller the RMSE generated, the more accurate the forecasting is. Here, the ES-TSK algorithm had a smaller RMSE value than time-series analysis. Also, Fig. 5 shows that ES-TSK fuzzy is closer to actual data. It shows that the system performance produced by combining the ES-TSK algorithm is more optimal than the comparable method of time-series analysis.

In the initial stages of testing, ES uses the popSize test to determine the number of initial chromosomes. This stage aims to produce the best optimal solution. In general, the increase of popSize may improve the fitness value because ES has a broader searching area. ES requires more time than the time series analysis. However, using the ES algorithm on the fuzzy rule coefficient is gradually improves the accuracy.

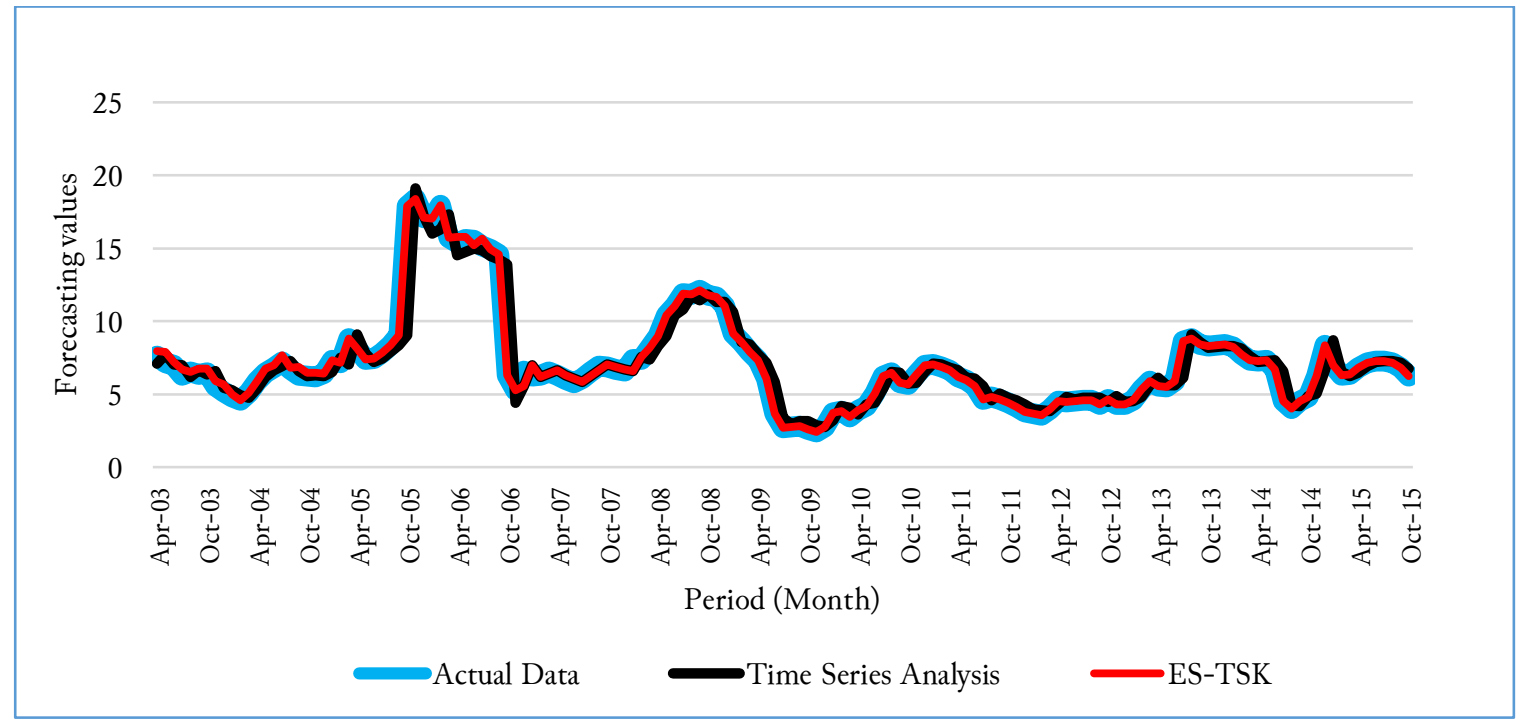

Fig. 5. The comparison between ES-TSK Fuzzy and the baseline time-series analysis.

\section{Conclusion}

Combining the evolution strategy algorithm and TSK fuzzy logic method produced a better result by applying the PopSize testing beforehand. ES-TSK showed more optimal performance as compared with the baseline. The error value that was generated by the combination of ES-TSK algorithms was 0.6201 . ES has a broader search area than the time series analysis. It produces better initial chromosomes as a base of fuzzy rules coefficient selection, which leads to the optimal solution of the inflation forecasting problem.

\section{Acknowledgment}

We want to say thanks to Knowledge Engineering and Data Science Research Center. The members help us reshaping the paper discussion. Finally, we would like to thank everybody important to the successful realization of this academic manuscript. This writing is far from perfect; constructivethoughtful suggestions and critics are welcomed.

\section{Declarations}

Author contribution. All authors contributed equally to the main contributor to this paper. All authors read and approved the final paper.

Funding statement. This research did not receive any specific grant from funding agencies in the public, commercial, or not-for-profit sectors.

Conflict of interest. The authors declare no conflict of interest.

Additional information. No additional information is available for this paper. 


\section{References}

[1] B. Al-Shboul, H. Faris, and N. Ghatasheh, "Initializing Genetic Programming using fuzzy clustering and its application in churn prediction in the telecom industry," Malaysian J. Comput. Sci., vol. 28, no. 3, pp. 213220, 2015, doi: 10.22452/mjcs.vol28no3.3.

[2] X. Han et al., "An Efficient Genetic Algorithm for Optimization Problems with Time-Consuming Fitness Evaluation," Int. J. Comput. Methods, vol. 12, no. 01, p. 1350106, Feb. 2015, doi: 10.1142/S0219876213501065.

[3] W. F. Mahmudy, R. M. Marian, and L. H. S. Luong, "Real Coded Genetic Algorithms for Solving Flexible Job-Shop Scheduling Problem - Part I: Modelling," Adv. Mater. Res., vol. 701, pp. 359-363, May 2013, doi: 10.4028/www.scientific.net/AMR.701.359.

[4] N. C. Long and P. Meesad, "Meta-heuristic algorithms applied to the optimization of type-1 and type 2 TSK fuzzy logic systems for sea water level prediction," in 2013 IEEE 6th International Workshop on Computational Intelligence and Applications (IWCIA), 2013, pp. 69-74, doi: 10.1109/IWCIA.2013.6624787.

[5] S. Elhag, A. Fernández, S. Alshomrani, and F. Herrera, "Evolutionary Fuzzy Systems: A Case Study for Intrusion Detection Systems," 2019, pp. 169-190, doi: 10.1007/978-3-319-91341-4_9.

[6] D. Mester and O. Bräysy, "Active guided evolution strategies for large-scale vehicle routing problems with time windows," Comput. Oper. Res., vol. 32, no. 6, pp. 1593-1614, Jun. 2005, doi: 10.1016/j.cor.2003.11.017.

[7] S. Siu, S.-S. Yang, C.-M. Lee, and C.-L. Ho, "Improving the Back-Propagation Algorithm Using Evolutionary Strategy," IEEE Trans. Circuits Syst. II Express Briefs, vol. 54, no. 2, pp. 171-175, Feb. 2007, doi: 10.1109/TCSII.2006.883226.

[8] F. Jiménez, G. Sánchez, J. M. García, G. Sciavicco, and L. Miralles, "Multi-objective evolutionary feature selection for online sales forecasting," Neurocomputing, vol. 234, pp. 75-92, 2017, doi: 10.1016/j.neucom.2016.12.045.

[9] S. Iqbal, C. Zhang, M. Arif, M. Hassan, and S. Ahmad, "A new fuzzy time series forecasting method based on clustering and weighted average approach," J. Intell. Fuzzy Syst., no. Preprint, pp. 1-10, 2020, doi: 10.3233/JIFS-179693.

[10] X. Xie, L. Lin, and S. Zhong, "Process Takagi-Sugeno model: A novel approach for handling continuous input and output functions and its application to time series prediction," Knowledge-Based Syst., vol. 63, pp. 46-58, Jun. 2014, doi: 10.1016/j.knosys.2014.03.012.

[11] J. L. Chavez-Hurtado and J. H. Cortes-Fregoso, "Forecasting Mexican inflation using neural networks," in 23rd International Conference on Electronics, Communications and Computing, CONIELECOMP2013, 2013, doi: 10.1109/CONIELECOMP.2013.6525753.

[12] B. Ruprecht et al., "Possibilistic Clustering Enabled Neuro Fuzzy Logic," in 2020 IEEE International Conference on Fuzzy Systems (FUZZ-IEEE), 2020, pp. 1-8, doi: 10.1109/FUZZ48607.2020.9177593.

[13] P. Nikdel, M. Hosseinpour, M. A. Badamchizadeh, and M. A. Akbari, "Improved Takagi-Sugeno fuzzy model-based control of flexible joint robot via Hybrid-Taguchi genetic algorithm," Eng. Appl. Artif. Intell., vol. 33, pp. 12-20, Aug. 2014, doi: 10.1016/j.engappai.2014.03.009.

[14] W.-H. Ho, S.-H. Chen, and J.-H. Chou, "Optimal control of Takagi-Sugeno fuzzy-model-based systems representing dynamic ship positioning systems," Appl. Soft Comput., vol. 13, no. 7, pp. 3197-3210, Jul. 2013, doi: 10.1016/j.asoc.2013.02.019.

[15] B. Gharleghi, A. Hassan Shaari, and N. Shafighi, "Predicting exchange rates using a novel 'cointegration based neuro-fuzzy system,'" Int. Econ., vol. 137, pp. 88-103, May 2014, doi: 10.1016/j.inteco.2013.12.001.

[16] Y. W. Kerk, K. M. Tay, and C. P. Lim, "Monotone Fuzzy Rule Interpolation for Practical Modelling of the Zero-Order TSK Fuzzy Inference System," IEEE Trans. Fuzzy Syst., 2021, pp. 1-1, doi: 10.1109/TFUZZ.2021.3057239. 
[17] Y. Cui, D. Wu, and J. Huang, "Optimize TSK Fuzzy Systems for Classification Problems: Minibatch Gradient Descent With Uniform Regularization and Batch Normalization," IEEE Trans. Fuzzy Syst., vol. 28, no. 12, pp. 3065-3075, 2020, doi: 10.1109/TFUZZ.2020.2967282

[18] A. G. Sarip, M. B. Hafez, and M. N. Daud, "Application Of Fuzzy Regression Model For Real Estate Price Prediction," Malaysian J. Comput. Sci., vol. 29, no. 1, pp. 15-27, Mar. 2016, doi: 10.22452/mjcs.vol29no1.2.

[19] G. L. Du, Z. Wang, C. Li, and P. X. Liu, "A TSK-type Convolutional Recurrent Fuzzy Network for Predicting Driving Fatigue," IEEE Trans. Fuzzy Syst., vol. 15, no. 5, pp. 1-1, 2020, doi: 10.1109/TFUZZ.2020.2992856.

[20] R. M. Pattanayak, H. S. Behera, and S. Panigrahi, "A novel probabilistic intuitionistic fuzzy set based model for high order fuzzy time series forecasting," Eng. Appl. Artif. Intell., vol. 99, p. 104136, Mar. 2021, doi: 10.1016/j.engappai.2020.104136.

[21] P.-C. Chang, J.-L. Wu, and J.-J. Lin, "A Takagi-Sugeno fuzzy model combined with a support vector regression for stock trading forecasting," Appl. Soft Comput., vol. 38, pp. 831-842, Jan. 2016, doi: 10.1016/j.asoc.2015.10.030.

[22] A. R. Lima, A. J. Cannon, and W. W. Hsieh, "Nonlinear regression in environmental sciences by support vector machines combined with evolutionary strategy," Comput. Geosci., vol. 50, pp. 136-144, Jan. 2013, doi: 10.1016/j.cageo.2012.06.023.

[23] N. R. Sari, W. F. Mahmudy, and A. P. Wibawa, "The effectiveness of hybrid backpropagation Neural Network model and TSK Fuzzy Inference System for inflation forecasting," J. Telecommun. Electron. Comput. Eng., 2017. Available at: Google Scholar.

[24] "Data Inflasi," Bank Indonesia. [Online]. Available: https://www.bi.go.id/id/statistik/indikator/datainflasi.aspx. [Accessed: 22-Oct-2015].

[25] E. J. Douglas, D. A. Shepherd, and C. Prentice, "Using fuzzy-set qualitative comparative analysis for a finergrained understanding of entrepreneurship," J. Bus. Ventur., vol. 35, no. 1, p. 105970, 2020, doi: 10.1016/j.jbusvent.2019.105970.

[26] F. A. Mohd-Rahim, C. Wang, H. Boussabaine, and H. Abdul-Rahman, "Risk prevention and deduction in software development using fuzzy membership function," Malaysian J. Comput. Sci., 2015, doi: 10.22452/mjcs.vol28no3.4.

[27] P. Prokopowicz and D. Ślęzak, "Ordered Fuzzy Numbers: Sources and Intuitions," 2017, pp. 47-56, doi: 10.1007/978-3-319-59614-3_3.

[28] R. Logambigai, S. Ganapathy, and A. Kannan, "Energy-efficient grid-based routing algorithm using intelligent fuzzy rules for wireless sensor networks," Comput. Electr. Eng., vol. 68, pp. 62-75, May 2018, doi: 10.1016/j.compeleceng.2018.03.036.

[29] D. Enke and N. Mehdiyev, "A Hybrid Neuro-fuzzy Model to Forecast Inflation," Procedia Comput. Sci., vol. 36, pp. 254-260, 2014, doi: 10.1016/j.procs.2014.09.088.

[30] P. Pirayesh, H. Motameni, and E. Akbari, "Comparison of two Defuzzification methods of Mean of Max and Central Average in Morphology of composition functions in Persian Sentences," J. Adv. Comput. Res., vol. 11, no. 2, pp. 17-29, 2020, available at : http://jacr.iausari.ac.ir/article_677113.html.

[31] M. G. Arjanaki and M. Pourgholi, "Takagi-Sugeno (TS) Fuzzy model-basedobserver design for glucoseinsulin system in diabetes type 1: An LMI approach," in 2020 28th Iranian Conference on Electrical Engineering (ICEE), 2020, pp. 1-5, doi: 10.1109/ICEE50131.2020.9260768.

[32] E. Salazar, "Integrating Evolution Strategies into Genetic Algorithms with Fuzzy Inference Evaluation to Solve a Steelmaking and Continuous Casting Scheduling Problem," In: Sim K., Kaufmann P. (eds) Applications of Evolutionary Computation, EvoApplications 2018, Lecture Notes in Computer Science, Springer, 2018, vol 10784, pp. 561-577, doi: 10.1007/978-3-319-77538-8_39. 
[33] W. F. Mahmudy, R. M. Mariana, and L. H. S. Luong, "Hybrid genetic algorithms for multi-period part type selection and machine loading problems in flexible manufacturing system," in 2013 IEEE International Conference on Computational Intelligence and Cybernetics (CYBERNETICSCOM), 2013, pp. 126-130, doi: 10.1109/CyberneticsCom.2013.6865795.

[34] Y. Wang, "A Genetic Algorithm with the Mixed Heuristics for Traveling Salesman Problem," Int. J. Comput. Intell. Appl., vol. 14, no. 01, p. 1550003, Mar. 2015, doi: 10.1142/S1469026815500030. 